\title{
Prevalência de sofrimento mental nos comerciários do Piauí durante a pandemia da
}

\section{Covid-19}

\author{
Prevalence of mental suffering in commerciaries in Piauí during the Covid-19 pandemic \\ Prevalencia del sufrimiento mental en comerciarios de Piauí durante la pandemia del Covid-19
}

Recebido: 05/02/2022 | Revisado: 10/02/2022 | Aceito: 19/02/2022 | Publicado: 28/02/2022

\author{
Emanuel Duarte Antao \\ ORCID: https://orcid.org/0000-0003-4372-7448 \\ Centro Universitário Uninovafapi, Brasil \\ E-mail: emanueldua@gmail.com \\ Carlos Antônio Meneses Carlos Filho \\ ORCID: https://orcid.org/0000-0001-8899-4086 \\ Centro Universitário Uninovafapi, Brasil \\ E-mail: carlinhos099@hotmail.com
}

\begin{abstract}
Resumo
A população mundial passa por uma Pandemia provocada pelo coronavírus, denominado também de COVID-19 ou SARS-Cov-2. Essa doença apresenta um quadro clínico que varia de infecções assintomáticas a quadros graves, podendo também ser confundida com um resfriado. No Brasil, o primeiro caso da doença foi notificado em 25 de fevereiro de 2020 e o número de acometidos pelo vírus tem crescido, desde então, gradativamente. Trata-se de um estudo transversal, descritivo de caráter analítico e quantitativo, cuja coleta de dados ocorrerá entre Julho de 2021 e Agosto de 2021, onde foi realizado em Teresina-PI. A amostra para o presente estudo foi dimensionada em 84 participantes considerando-se uma população de 10.903 comerciários cadastrados no SINDCOM, em Teresina. Os instrumentos de coleta de dados serão os questionários, (SRQ 20 - Self Report Questionnaire), DASS - 21, DAST-20 e o de Identificação do usuário e de condições de trabalho. Os resultados obtidos nos questionários aplicados, demonstraram que, $30,12 \%$ da população em estudo, está com sofrimento mental e 69,88 não tem critérios que demonstrem está com sofriemnto mental. A análise das respostas dadas pelos participantes nas questões de natureza sociodemográfica pelo teste de Qui-quadrado, apresentou, em sua maioria, independência dos resultados obtidos na avaliação do sofrimento mental pelo SRQ-20, ou seja, as respostas dadas a essas questões não eram significativamente diferentes $(p>0,05)$ nas pessoas com sofrimento mental medido pelo SRQ-20 do que naquelas que não apresentavam sofrimento mental.
\end{abstract}

Palavras-chave: Ansiedade; Depressão; Covid-19.

\begin{abstract}
The world population is experiencing a pandemic caused by the coronavirus, also called COVID-19 or SARS-Cov-2. This disease presents a clinical picture that varies from asymptomatic infections to severe conditions, and can also be confused with a cold. In Brazil, the first case of the disease was notified on February 25, 2020 and the number of people affected by the virus has been growing gradually since then. This is a cross-sectional, descriptive, analytical and quantitative study, whose data collection will take place between July 2021 and August 2021, where it was carried out in Teresina-PI. The sample for the present study was dimensioned in 84 participants considering a population of 10,903 commercial workers registered in SINDCOM, in Teresina. The data collection instruments will be the questionnaires (SRQ 20 - Self Report Questionnaire), DASS - 21, DAST-20 and the User Identification and Working Conditions. The results obtained in the questionnaires applied showed that $30.12 \%$ of the study population has mental suffering and 69.88 does not have criteria to demonstrate that they have mental suffering. The analysis of the answers given by the participants to the questions of a sociodemographic nature by the Chi-square test, showed, for the most part, independence from the results obtained in the assessment of mental suffering by the SRQ-20, that is, the answers given to these questions were not significantly different $(p>0.05)$ in people with mental distress measured by the SRQ-20 than in those without mental distress.
\end{abstract}

Keywords: Anxiety; Depression; Covid-19.

\section{Resumen}

La población mundial está experimentando una pandemia causada por el coronavirus, también llamado COVID-19 o SARS-Cov-2. Esta enfermedad presenta un cuadro clínico que varía desde infecciones asintomáticas hasta afecciones graves, pudiendo también confundirse con un resfriado. En Brasil, el primer caso de la enfermedad se notificó el 25 de febrero de 2020 y el número de personas afectadas por el virus ha ido creciendo gradualmente desde entonces. Se trata de un estudio transversal, descriptivo, analítico y cuantitativo, cuya recogida de datos se llevará a cabo entre julio de 2021 y agosto de 2021, donde se llevó a cabo en Teresina-PI. La muestra para el presente estudio se dimensionó en 84 
participantes considerando una población de 10,903 trabajadores comerciales registrados en SINDCOM, en Teresina. Los instrumentos de recolección de datos serán los cuestionarios (SRQ 20 - Self Report Questionnaire), DASS - 21, DAST-20 y la Identificación de Usuario y Condiciones Laborales. Los resultados obtenidos en los cuestionarios aplicados mostraron que el 30,12\% de la población de estudio padece trastornos mentales y el 69,88 no tiene criterios para demostrar que padecen trastornos mentales. El análisis de las respuestas dadas por los participantes a las preguntas de carácter sociodemográfico mediante la prueba de Chi-cuadrado, mostró, en su mayor parte, independencia de los resultados obtenidos en la valoración del sufrimiento mental por el SRQ-20, es decir, las respuestas dadas a estas preguntas no fueron significativamente diferentes $(\mathrm{p}>0.05)$ en personas con distrés mental medido por el SRQ-20 que en aquellos sin distrés mental.

Palabras clave: Ansiedad; Depresión; Covid-19.

\section{Introdução}

A população mundial passa por uma Pandemia provocada pelo coronavírus, denominado também de COVID-19 ou SARS-Cov-2. Essa doença apresenta um quadro clínico que varia de infecções assintomáticas a quadros graves, podendo também ser confundida com um resfriado. No Brasil, o primeiro caso da doença foi notificado em 25 de fevereiro de 2020 e o número de acometidos pelo vírus tem crescido, desde então, gradativamente. Trata-se de um estudo transversal, descritivo de caráter analítico e quantitativo, cuja coleta de dados ocorrerá entre Julho de 2021 e Agosto de 2021, onde foi realizado em Teresina-PI. A amostra para o presente estudo foi dimensionada em 84 participantes considerando-se uma população de 10.903 comerciários cadastrados no SINDCOM, em Teresina. Os instrumentos de coleta de dados serão os questionários, (SRQ 20 - Self Report Questionnaire), DASS - 21, DAST-20 e o de Identificação do usuário e de condições de trabalho. Os resultados obtidos nos questionários aplicados, demonstraram que, 30,12\% da população em estudo, está com sofrimento mental e 69,88 não tem critérios que demonstrem está com sofriemnto mental. A análise das respostas dadas pelos participantes nas questões de natureza sociodemográfica pelo teste de Qui-quadrado, apresentou, em sua maioria, independência dos resultados obtidos na avaliação do sofrimento mental pelo SRQ-20, ou seja, as respostas dadas a essas questões não eram significativamente diferentes ( $p>0,05$ ) nas pessoas com sofrimento mental medido pelo SRQ-20 do que naquelas que não apresentavam sofrimento mental.

A população mundial passa por uma Pandemia provocada pelo coronavírus, denominado também de COVID-19 ou SARS-Cov-2. Essa doença apresenta um quadro clínico que varia de infecções assintomáticas a quadros graves, podendo também ser confundida com um resfriado. Os sintomas da COVID-19 podem ser caracterizados pela presença de: sensação febril ou febre associada a dor de garganta, dor de cabeça, tosse, coriza, ou até mesmo uma pneumonia grave. O diagnóstico pode ser realizado a partir da clínica do paciente, considera-se também o diagnóstico clínico-epidemiológico, pelo contato que o mesmo veio a ter com pessoas infectadas ou com sintomas nos últimos 14 dias do aparecimento dos sintomas; diagnóstico clínicoimagem, pela analise da tomografia em paciente que já estão com um quadro respiratório associado a febre; Diagnostico laboratorial, onde será realizado exames como o RT-PCR, imunocromatografia (teste rápido), Ensaio Imunoenzimatico (ELISA), Ensaio por Eletroquimioluminescencia (Ministério da Saúde, 2020).

No último relatório da OMS, publicado em 17 de Dezembro de 2020, estão documentados 72.851 .747 casos confirmados, 1.643.339 mortes, com registro em países de todas as regiões do mundo. No Brasil, o primeiro caso da doença foi notificado em 25 de fevereiro de 2020 e o número de acometidos pelo vírus tem crescido, desde então, gradativamente. O Brasil confirmou 7.504.833 casos e 191.570 mortes até a tarde do dia 28 de Dezembro de 2020. No Piauí , a Secretaria da Saúde confirmou até o dia 28 de Dezembro de 2020,140.749 casos, sendo que 2.815 foram a óbito ( Organização mundial da saude, 2020).

Estudos com a população da China, primeiro país que adotou a quarentena e o isolamento social como medidas protetivas à disseminação do novo coronavírus, indicam que há possíveis consequências psicológicas desse confinamento em massa. Os resultados mostraram maior índice de ansiedade, depressão, uso nocivo de álcool e menor bem-estar mental do que os índices populacionais usuais. De forma geral, pacientes com confirmação ou suspeita da COVID-19 podem sentir medo das 
consequências da infecção - potencialmente fatal, e os que estão em quarentena podem sentir tédio, solidão e raiva. Além disso, observam-se perdas econômicas nos locais mais atingidos e crescente preocupação com as consequências práticas da pandemia no setor econômico. Tem sido visto, por exemplo, que o estresse devido às perdas financeiras seria um risco psicossocial muito comum em momentos de recessão econômica, pobreza e desemprego, ou seja, esses são fatores que também poderiam afetar negativamente a saúde mental dos indivíduos durante esse episódio pandêmico, de acordo com, Quadros e col. (2020).

Os transtornos depressivos constituem um grave problema de saúde pública, devido a sua alta prevalência, repercussões na saúde geral e impacto psicossocial. Segundo o Diagnostic and Statistical Manual of Mental Disorders (DSM-V), são critérios para diagnóstico de depressão: estado deprimido (sentir-se deprimido a maior parte do tempo); anedonia: interesse diminuído ou perda de prazer para realizar as atividades de rotina; sensação de inutilidade ou culpa excessiva; dificuldade de concentração: habilidade frequentemente diminuída para pensar e concentrar-se; fadiga ou perda de energia; distúrbios do sono: insônia ou hipersonia praticamente diárias; problemas psicomotores: agitação ou retardo psicomotor; perda ou ganho significativo de peso, na ausência de regime alimentar; ideias recorrentes de morte ou suicídio, segundo Gonçalves et al., (2017) .

De acordo com Fernandes e COL (2017), os dados da Organização Mundial de Saúde (OMS) apontam que a prevalência mundial do transtorno de ansiedade (TA) é de 3,6\%. No continente americano esse transtorno mental alcança maiores proporções e atinge 5,6\% da população, com destaque para o Brasil, onde o TA está presente em 9,3\% da população, possuindo o maior número de casos de ansiedade entre todos os países do mundo. Essas estatísticas são reflexos da dinâmica da sociedade moderna, que contribui para o surgimento de transtornos mentais e comportamentais, sobretudo a ansiedade, o estresse e a depressão, que se tornaram doenças muito comuns nos consultórios médicos. Essas doenças podem ser resultado da exposição a fatores de risco advindos da atividade laboral e também das relações construídas no ambiente de trabalho. Baseado nisso, Até que ponto a Pandemia e as medidas restritivas afetaram a saúde mental dos comerciários do estado do Piauí? O trabalho tem por objetivo geral, estudar a prevalência da Depressão, Ansiedade e uso de drogas nos comerciários do Estado do Piauí., e objetivos específicos, identificar a prevalência do sofrimento mental nos comerciários de Teresina-PI durante o período da Pandemia da Covid-19, relacionar os impactos econômicos com o sofrimento mental durante a Pandemia e identificar a prevalência de fatores sociodemográficos com o sofrimento mental durante a Pandemia.

\section{Metodologia}

Trata-se de um estudo transversal, descritivo de caráter analítico e quantitativo, cuja coleta de dados ocorrerá entre Julho de 2021 e Agosto de 2021. O estudo será realizado em Teresina-PI. A coleta de dados será realizada entre Julho 2021 e Agosto de 2021. A amostra para o presente estudo foi dimensionada em 84 participantes considerando-se uma população de 10.903 comerciários cadastrados no SINDCOM, em Teresina. O cálculo amostral considerou o procedimento de cálculo de amostra para uma população finita, com erro amostral limitado a $5 \%$ e grau de confiança de $95 \%$. Para tanto, assumiu-se ainda para a população em estudo a prevalência de 5,8\% de depressão encontrada na população geral (Gonçalves, 2018). A amostra será composta por trabalhadores cadastrados no Sindicato dos Comerciários de Teresina (SINDCOM).

Utilizou-se critérios de inclusão para o trabalho ser realizado, tais como: ser cadastrado no SINDCOM, ter como principal fonte de renda o comercio, ser maior de 18 anos e concordar com a participação assinando o Termo de consentimento livre e esclarecido (TCLE). Foi inseridos critérios de exclusão, tais como, pessoas menores de 18 anos; não ser cadastrado no órgão SINDCOM, não concordância do participante e não responder o questionário de forma completa. Os instrumentos de coleta de dados serão os questionários, (SRQ 20 - Self Report Questionnaire), DASS - 21, DAST-20 e o de Identificação do usuário e de condições de trabalho. Os dados obtidos no estudo serão analisados no Programa SPSS 18.0 após digitação e conferência dos valores apontados nos formulários individuais. A sumarização dos valores apontados pelos participantes da pesquisa ocorrerá por meio do cálculo da média e desvio padrão para as variáveis contínuas e das frequências absolutas e relativas 
para variáveis categóricas e nominais. As verificações das relevâncias das contribuições e da associação entre as diferentes variáveis no estudo serão determinadas, respectivamente, por meio de Análise Fatorial e Análise de Componentes Principais, seguida da Análise de Correlação mais adequada ao tipo de variável em foco. O presente estudo adotará o valor $\mathrm{p}>0,05$ na avaliação da significância estatística dos testes realizados.

A coleta de dados será realizada pelos pesquisadores entre Julho de 2021 e Agosto de 2021. Nesse período, ao participante será enviado um questionário no Google Forms via WhatsApp ou e-mail. O questionário a ser enviado irá utilizar as Escalas de Ansiedade e Depressão de Beck para analisar o grau de severidade no qual se encontra o comerciário, a partir da escala Likert, no qual se trata de perguntas simples e objetivas.

Dentro do mesmo questionário será incluído a escala DAST-20, onde irá mensurar a gravidade do uso de drogas por a classe a ser estudada.

O participante será esclarecido sobre quaisquer duvidas sobre o questionário abordado, para a explicação dos objetivos e possíveis riscos do estudo. Caso aceite participar do estudo, será apresentado o Termo de Consentimento Livre e Esclarecido (TCLE). No Formulário não haverá nenhuma forma de identificação do participante. Ao participante que demonstrar algum resultado preocupante será disponibilizado o apoio necessário, através de panfletos que orientem sobre a saúde mental e locais para buscar a assistência necessária.

\section{Resultados e Discussão}

Os resultados obtidos a seguir, foram obtidos através da aplicação dos questionários avaliados e que demonstraram Distribuição de frequências dos participantes da pesquisa quanto ao enquadramento no critério de sofrimento mental após aplicação do questionário SRQ-20, Contribuições médias de cada grupo de sintomas avaliados no SRQ-20 para o escores final dos pacientes rastreados com sofrimento mental, Frequências de respostas "sim" em cada uma das questões do formulário SRQ-20 aplicadas a trabalhadores do comércio em Teresina.

\section{Análise Resultados SRQ-20}

Figura 1: Distribuição de frequências dos participantes da pesquisa quanto ao enquadramento no critério de sofrimento mental após aplicação do questionário SRQ-20.

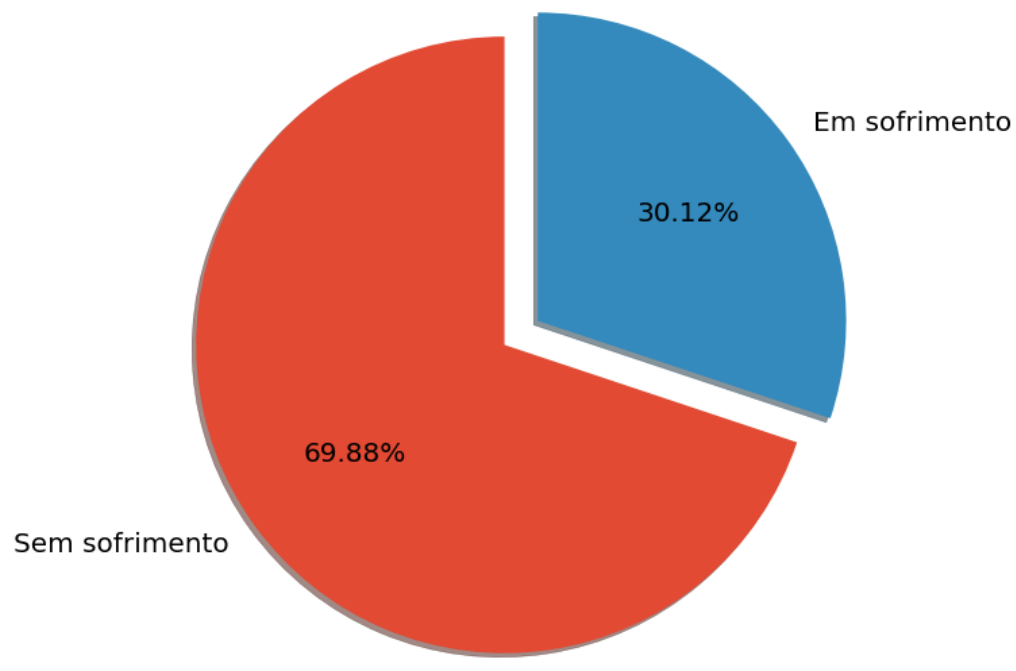

Fonte: Autores.

A Figura 2 a seguir analisa as características dos entrevistados que se enquadraram na categoria em sofrimento do Gráfico 1. 
Figura 2: Contribuições médias de cada grupo de sintomas avaliados no SRQ-20 para o escores final dos pacientes rastreados com sofrimento mental.

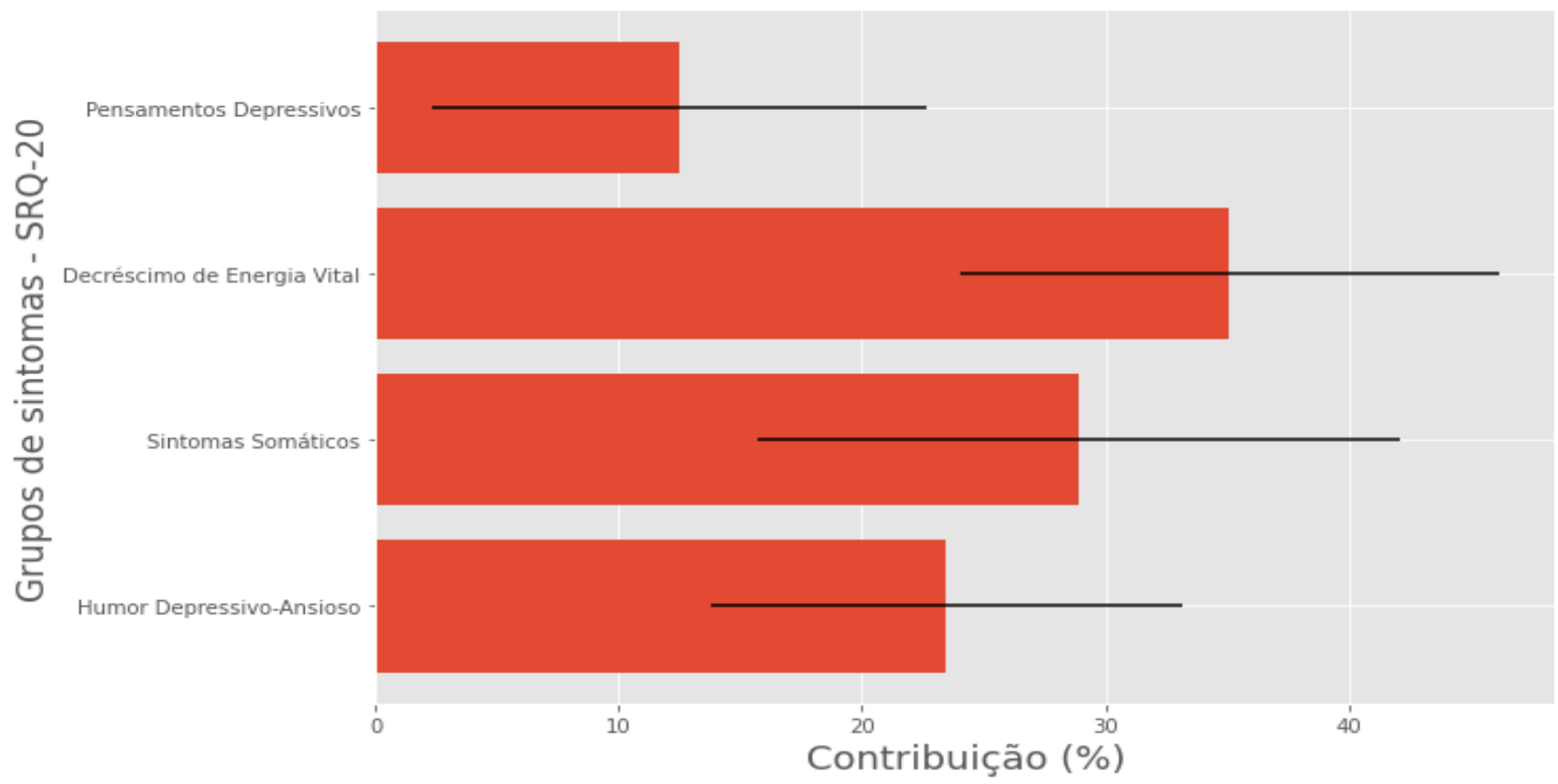

Fonte: Autores.

Na Figura 2 é possível observar que os quatro tipos de sintomas avaliados no SRQ-20 contribuíram de forma distinta para a formação do escore de sofrimento mental dos participantes avaliados. Após avaliação dos dados obtidos na construção dos escores por meio do teste Kruskal-Waliis, foi possível determinar que o grupo de sintomas enquadrados como pensamentos depressivos apresentaram uma contribuição significativamente menor $(\mathrm{p}<0,05)$ na constituição dos escores totais de participantes da avaliação quando comparadas aos outros três grupos de sintomas. Os demais grupos de sintomas não demostraram, entre si, diferenças significativas de contribuição para o escore total daqueles que apresentaram sofrimento mental, conforme o mesmo teste Kruskal-Waliis.

Figura 3: Frequências de respostas "sim" em cada uma das questões do formulário SRQ-20 aplicadas a trabalhadores do comércio em Teresina.

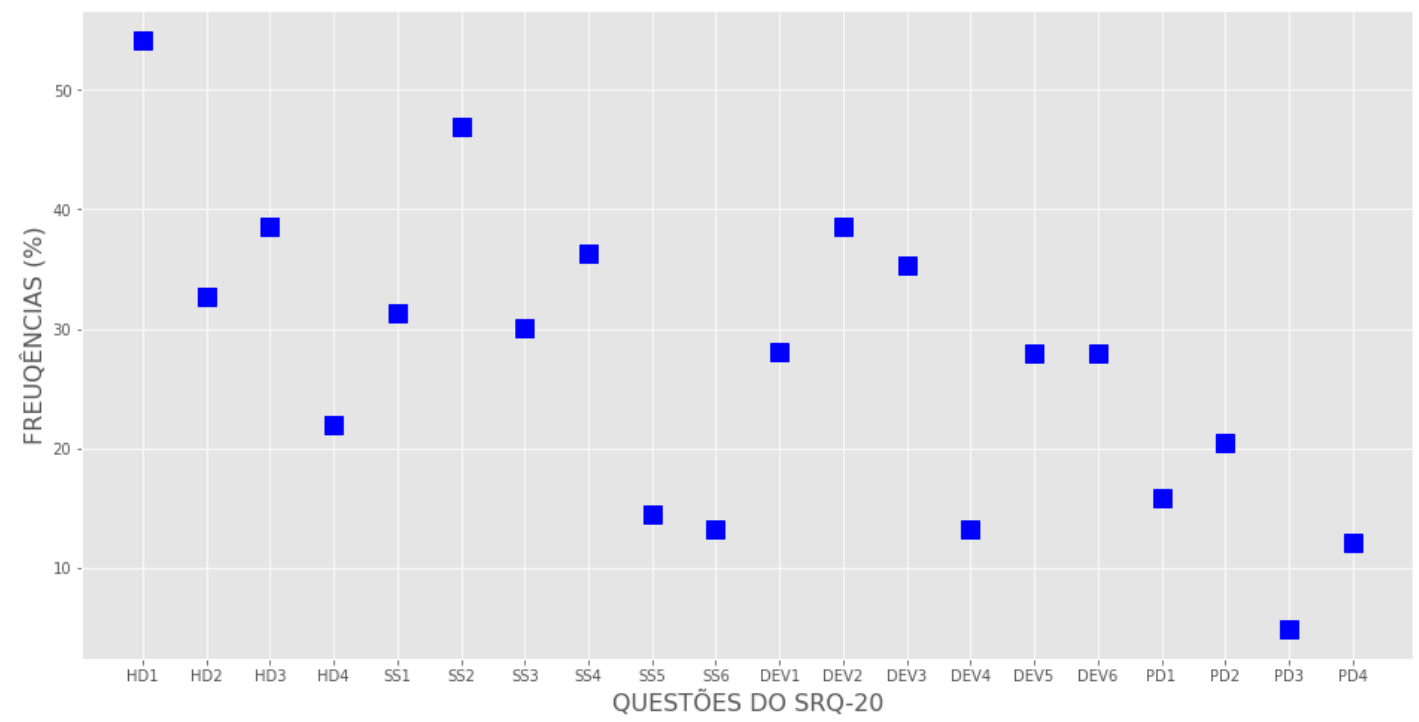

Fonte: Autores. 
Research, Society and Development, v. 11, n. 3, e38911326606, 2022

(CC BY 4.0) | ISSN 2525-3409 | DOI: http://dx.doi.org/10.33448/rsd-v11i3.26606

Tabela 1: Caracterização dos participantes da pesquisa que apresentaram sofrimento mental avaliado pelo SRQ-20.

\begin{tabular}{|c|c|c|}
\hline Variável & $\mathbf{N}$ & $\%$ \\
\hline \multicolumn{3}{|l|}{ Sexo } \\
\hline Feminino & 17 & 68 \\
\hline Masculino & 8 & 32 \\
\hline \multicolumn{3}{|l|}{ Idade } \\
\hline $20-30$ anos & 7 & 28 \\
\hline $31-40$ anos & 11 & 44 \\
\hline Mais de 40 anos & 7 & 28 \\
\hline \multicolumn{3}{|l|}{ Situação conjugal } \\
\hline Casado & 13 & 52 \\
\hline Divorciado & 1 & 4 \\
\hline Solteiro & 11 & 44 \\
\hline União Estável & 0 & 0 \\
\hline \multicolumn{3}{|l|}{ Escolaridade } \\
\hline Ensino fundamental & 3 & 12 \\
\hline Ensino médio & 15 & 60 \\
\hline Graduação & 7 & 28 \\
\hline Pós-graduação & 0 & 0 \\
\hline
\end{tabular}

Fonte: Autores.

Quadro 1: Características da atuação profissional dos participantes da pesquisa que demonstraram associação com o sofrimento mental avaliado pelo SRQ-20.

\begin{tabular}{|l|}
\hline \multicolumn{1}{|c|}{ Variáveis* } \\
\hline Sofre pressão para realizar tarefas que não fazem parte das atribuições do seu cargo? \\
\hline Está ou esteve em tratamento psicológico/psiquiátrico nos últimos 12 meses? \\
\hline O trabalho exige demais? \\
\hline Tem tempo suficiente para cumprir todas as tarefas de seu trabalho? \\
\hline O trabalho costuma apresentar exigências? \\
\hline Tem história de acidente de trabalho e/ou doença relacionada ao trabalho? \\
\hline
\end{tabular}

Fonte: Autores. 
A análise das respostas dadas pelos participantes nas questões de natureza sociodemográfica pelo teste de Qui-quadrado, apresentou, em sua maioria, independência dos resultados obtidos na avaliação do sofrimento mental pelo SRQ-20, ou seja, as respostas dadas a essas questões não eram significativamente diferentes ( $p>0,05)$ nas pessoas com sofrimento mental medido pelo SRQ-20 do que naquelas que não apresentavam sofrimento mental. A exceção a este comportamento foi notada apenas nas seis questões elencadas no Quadro 1. Nestas questões, as respostas obtidas apresentaram-se significativamente diferentes $(p<0,05)$ naqueles que apresentaram sofrimento mental e em comparação com aqueles que não. Tal achado indica a associação entre os resultados das questões do Quadro 1 e o resultado dos SRQ-20.

\section{Análise Resultados DASS-21}

Tabela 2: Distribuição por frequências relativas $(\%)$ das subescalas de Ansiedade, depressão e estresse de participantes $(\mathrm{n}=82)$ submetidos à avaliação pelo DASS-21.

\begin{tabular}{lccc}
\hline Níveis da DASS & Ansiedade & Depressão & Estresse \\
\hline Normal & 82,9 & 75,6 & 85,4 \\
Mínimo & 0 & 3,7 & 6,1 \\
Moderado & 12,2 & 14,6 & 6,1 \\
Grave & 1,2 & 3,7 & 2,4 \\
Muito Grave & 3,7 & 2,4 & 0 \\
\hline
\end{tabular}

Fonte: Autores.

De acordo com a tabela e do estudo dela, percebe-se que, que os níveis de DASS são variados quanto aos critérios avaliados.

\section{Conclusão}

O trabalho mostrou, através dos questionários aplicados que, existe sim, um percentual de sofrimento mental na classe estudada, onde, junto com os critérios avaliados e com a estatística referida, mostra-se um nível de sofrimento metal considerado modera-alto, de 30,12\% de acordo com o questionário validado SRQ. O DASS-21, é um teste de depressão, ansiedade e stress que mede os níveis desses transtornos a partir de comportamentos e sensações experimentados nos últimos dias, no caso, avaliado no período da Pandemia, os resultados mostraram-se relevantes, pois, mostrou uma frequência relativa de $3,7 \%$ no quadro de ansiedade, considerada grave.

\section{Referências}

Fernandes, M. A., Ribeiro, H. K. P., Santos, J. D. M., Monteiro, C. F. S., Costa, R. S., Soares, R. F. S. Prevalence of anxiety disorders as a cause of workers' absence. Rev Bras Enferm [Internet]. 2018;71(Suppl 5):2213-20. [Thematic Issue: Mental health] DOI: http://dx.doi.org/10.1590/0034-7167-2017-0953

Duarte, M. de Q. et al. COVID-19 e os impactos na saúde mental: uma amostra do Rio Grande do Sul, Brasil. Ciênc. saúde coletiva, Rio de Janeiro v.25, n. 9, p. 3401-3411, Sept. 2020.://www.scielo.br/scielo.php?script=sci_arttext\&pid=S141381232020000903401\&lng=en\&nrm

Goncalves, A. M. C. et al. Prevalência de depressão e fatores associados em mulheres atendidas pela Estratégia de Saúde da Família. J. bras. psiquiatr., Rio de Janeiro, v. 67, n. 2, p. 101-109, June 2018 . <http://www.scielo.br/scielo.php?script=sci_arttext\&pid=S0047-2085 2018000200101\&lng=en\&nrm=iso>. 
Research, Society and Development, v. 11, n. 3, e38911326606, 2022

(CC BY 4.0) | ISSN 2525-3409 | DOI: http://dx.doi.org/10.33448/rsd-v11i3.26606

Teng, C. T.; Humes, E.de C.; Demetrio, F. N. Depressão e comorbidades clínicas. Rev. psiquiatr. clín., São Paulo , v. 32, n. 3, p. 149-159, June 2005 . <http://www.scielo.br/scielo.php?script=sci_arttext\&pid=S0101-60832005000300007\&lng=en\&nrm=iso>.

Gonsalez, E. et al. Ansiedade e depressão entre profissionais de programas de aprimoramento profissional. Artigo de investigação. Disponível em: http://dx.doi.org/10.19131/rpesm.0192.

Fleck, M. P. et al. Revisão das diretrizes da Associação Médica Brasileira para o tratamento da depressão (Versão integral). Rev. Bras. Psiquiatr., São Paulo , v. 31, supl. 1, p. S7-S17, May 2009. Available from <http://www.scielo.br/scielo.php?s

Organização Pan-Americana da Saúde.Considerações psicossociais e de saúde mental durante o surto de COVID-19. Brasília (DF); 2020.

Laurentino, S.G.; S.L. de Souza et al. Tomada de decisão em pacientes com depressão maior: aspectos comportamentais e eletrofisiológicos. Revista Brasileira de Psiquiatria, São Paulo, v. 40, 2018. https://repositorio.ufpe.br/handle/123456789/16468 